\title{
Linguistic Signs and Meanings between Material and Relational Processes in Cyber-based Interactive Responses towards the Transgenderism Issue: A Semiotic and SFL Perspective
}

\author{
Marsandi Manar ${ }^{1}$, Aceng Ruhendi Saifullah ${ }^{2}$, Dadang Sudana ${ }^{3}$ \\ \{manaryana_dianmaya@yahoo.co.id ${ }^{1}$, acengruhendisaifullah@upi.edu ${ }^{2}$,dsudana2013@yahoo.com ${ }^{3}$ \}
}

Universitas Pendidikan Indonesia, Indonesia

\begin{abstract}
This SFL and semiotic study scrutinizes the linguistic signs and meanings built in the interactive comments responding to a suspected transgenderism issue of post genital reconstruction surgery of an Indonesian celebrity that has been viral on YouTube. Specifically, this study limits the focus of its analysis on material and relational processes. 144 comments in Indonesian towards a YouTube video of more than 2 million views were analyzed for their transitivity of material and relational processes by employing the tables of analysis adapted from Halliday's experiential meaning framework. Then the analyzed constituents of transitivity were further interpreted based on the categorization of linguistic signs built by responders. Findings of this study reveal that responders in cyber media employed similar and different functional strategies in building signs and meanings towards the taboo and sensitive transgender issue in the Indonesian context, as shown by the evidences of scrutiny on the linguistic features.
\end{abstract}

Keywords: Linguistic Signs, Meanings, Material Process, Relational Process, Transgender Issue, Interactive Cyber Media, Semiotic, SFL

\section{Introduction}

The signs in nature, social, and culture are transformed by human beings into meanings through their cognitive processes [1]. Further, as pointed out by Peirce in Hoed, signs are not perceived as a kind of structure to be 'imaged' in cognition but rather as a semiotic process involving threefold cognitive phases departing from something that can be sensed or thought [1]. Peirce proposes that the first stage of semiotic processes refers to the perception of representamen as the real object that is directly perceived by humans' senses [1]. The second phase is associated with the reference of spontaneous representamen towards an object as a concept that is seen by the users of signs within their cognition. The third stage is defined as further interpretation termed interpretant after the representamen is linked with the object. Peirce in Hoed concludes that the process of interpreting signs does not occur in one single episode but rather in continuity or even in unlimited flow since each interpretation process develops into a new representation [1] as depicted below. 


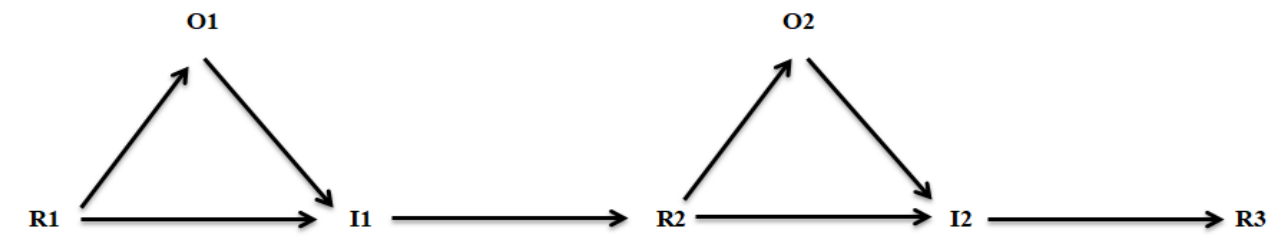

Fig. 1. Unlimited Semiosis.

$R$ in Peirce's semiotic scheme above stands for the representation of object $(\mathrm{O})$ where meaning as the result of the connection of both is interpreted by interpretant (I). Then new representation is produced by interpretant and this occurs continuously. Under the interactive mode of discourse such as the interaction among responders in cyber media characterized by Herring's principles of interactivity, demassification, asynchronous, and simultaneous, the pattern of Peirce's semiotic model is best at work.

In this current study, the representation is linked to Halliday's SFL transitivity built by responders towards the issue of transgenderism especially the suspected issue of a post-genital reconstruction surgery of a celebrity broadcasted through YouTube Channel. Emilia et al. [2] claim that Halliday's SFL views language as a semiotic system and the most complete of signs while Engelmo [3] points out that Halliday's and Matthiessen's SFL approaches language as a semiotic system, that is, a tool that relies on semiotic to be able to function. Halliday and Matthiessen [4] theories that:

"The transitivity system construes the world of experience into a manageable set of PROCESS TYPES. Each process type provides its own model or schema for construing a particular domain of experience as a figure of a particular kind".

The process in Halliday's SFL plays the fundamental role in representing all experiences in context in a form of clauses generally termed 'clause as representation' of the world consisting of embedded participants and optional circumstances [4]. Martin et al. [5] reiterate that all types of processes are symbolized through clauses along with embedded participants (animate and inanimate), various attributes, and circumstances attached to the process. More specific, the processes are classified as material process construing the event of happening/doing; mental process representing the event of thinking, sensing, and feeling; behavioral process revealing the reaction of human psychology resulted in noticeably physical reaction; verbal process showing human saying activities; relational process creating the generalization or experience relation building; and existential process representing the existence of something [4]. Martin et al. [5] portray the scheme of process with its elements in a diagram as follows. 


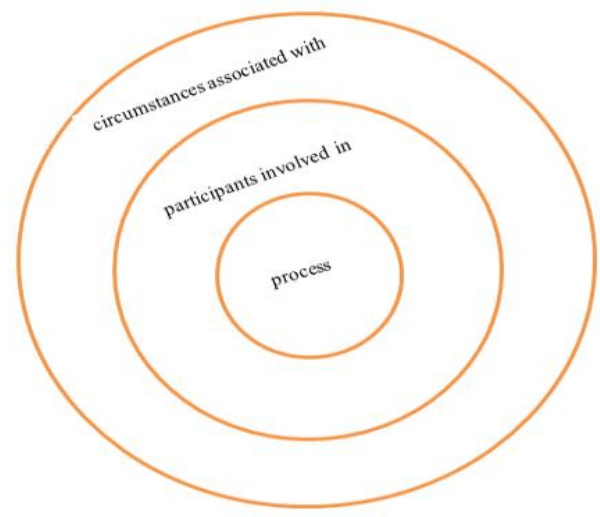

Fig. 2. Transitivity Structure.

The most common process in the system of transitivity refers to the material process. A material process in a simple way is associated with the process of happening and doing [4]. Further, it is pointed out that within a material process framed in a clause an entity of change is revealed through the flow of events occurring via some input of energy [4]. The plausibility behind the material process can be tested by asking what did $x$ do? and what did $x$ do to $y$ ? [6]. The $x$ is associated with the first participant termed actor while the $y$ refers to the main second participant known as goal. Halliday and Matthiessen [4] in general propose that the actor in the material process is "the source of the energy bringing about the change" and consider the goal as "the second participant that is directed at or extended to".

Another most common process in the system of transitivity is the relational process that Halliday and Matthiessen [4] point out as the process of being and having. Martin et al. [5] reiterate that the relational process can either refer to the process of giving attributes (attributive) or refer to the process of establishing symbolization (identifying). They also confirm Halliday's framework that an attributive clause has participant one as the carrier and participant two as the attribute while an identifying clause comprises of a first participant termed token (identified) and a second participant named value (identifier). The plausibility behind an attributive clause is that the second participant is a member of the first participant and this makes both irreversible while in an identifying clause the participant one and two can be reversible due to its equal representation of identity [5].

As the representation of humans' experiences, the system of transitivity has been found to play roles in achieving certain goals brought by media [7-20]. More specific, under the discourse of media where information and ideology are developed, disseminated, and maintained in favor of acceptance, linguistic strategies especially the system of transitivity have been found to be driven based on the ideology brought by media [10-13][17][19-21], The system of transitivity serves to achieve this goal through the choices of types of process, participants and circumstances.

Studies on the language of media have revealed that material and verbal clauses have been found to be dominant in comparison with other types of processes [8][17]. However, other studies have also found that material and relational processes outnumbered other types of processes [11][13][16][22]. Manar's study on the one-way comments posted on Facebook reports that material and relational processes were found to be dominant compared with verbal, mental, behavioral, and existential processes [22]. More important, the preliminary scrutiny of 
this current study investigating the linguistic signs and meanings in the interactive comments towards the issue of transgender on YouTube has pointed out that the frequency of material and relational processes significantly surpassed other types of processes. Besides, from the perspective of scientific language where fact creation is emphasized, in general, material and relational were also traced to be dominant in comparison with other types of processes [23-30).

To the present time, the dissemination of information and ideology has not merely been brought by conventional media with their rather authoritative and one-way communication, but also by cyber or online-based media which allow comments or responses from responders around the globe with no limit of time and border. It has been claimed that the interactive cyberbased media can cater for democratization by allowing public involvement, freedom of expression, as well equal power relations between the producers and users [31]. The emergence of cyber media provides circumstances for any parties regardless of authority to disseminate ideas including beliefs. More important, related with verbal activities, it has been pointed out that cyber-based media provide rich contexts where interactive verbal phenomena and the relationship between discourse and social practice can be studied or investigated [32]. As reported by Herring, the sporadic utilization of cyber media in the 21 st century is underpinned by their characteristics of interactivity, demassification, asynchronous, and simultaneous [33].

Interactivity depicts that the nature of interaction in the cyber media can be two ways or even multi ways and this is different with the one-way pattern of interaction in the conventional media. These characteristic hints that the style of interaction in cyber media adopts bottom-up communication in comparison with the conventional media that provide top-down style of communication. Saifullah [31] in his linguistic studies in cyber media has proved that this type of bottom-up communication also reflects that responder in the cyber media do not only play roles as the consumers of discourse but also as the producers of discourse. Responders can support, maintain, argue, even deny the propositions bringing by media. Another characteristic of cyber media, demassification, provides limitless coverage either in terms of the numbers of responders or in terms of location. This characteristic creates spaces for any parties to participate regardless of their distance. The last two characteristics, asynchronous and simultaneous, imply that the communication and interaction occurring in cyber media can be either at the same time (simultaneously) or in different times (asynchronously). Comments from responders to the signs and meanings brought by cyber media do not depend on restricted time. As long as the texts have not been blocked or omitted by the administrators, responses can be posted at any time.

Due to the bottom-up and open-ended characteristics that they bring, the nature of communication and interaction in cyber media including their linguistic features has been the focus of interdisciplinary studies especially. One of existing studies investigating the nature of communication and interaction in cyber media as shown by the linguistic evidences is the CMD and semiotic study conducted by Saifullah [31]. The study depicts linguistic features framed in the occurrences of democracy in the interaction between responders and cyber media as well as among responders in addressing the issue of Kuningan Bombing 2 in Jakarta in 2 July 2009. The study reports that the interaction between cyber media and responders occurred in one episode whereas the one among responders occurred in two or more episodes. In delineating its problems, Saifullah's CMD and semiotic-based study [33] adopts the characteristic of cyber media proposed by Herring, namely interactivity, demassification, asynchronous, and simultaneous.

One of the most current media with the characteristics of Herring's model of interactivity, demassification, asynchronous, and simultaneous refers to YouTube Channel. This mode of cyber-based communication and interaction allows cyber society to post and spread videos that can be openly commented by cyber responders [34] regardless of time and space borders. Khan 
reports in his study [35] that responders in YouTube were able to engage in written conversation addressing the ads broadcasted via YouTube Channel. Based on another study, users in YouTube were found not only as the consumers of the information brought by the video but also as responders that commented on the videos posted by other users [36]. Due to its functions and characteristics that meet the needs of cyber generation, YouTube Channel has been gaining popularity especially in 4.0 society. It has been claimed to have achieved popularity par excellence among other similar online media in terms of digital contents [37]. To the present time, YouTube Channel has been the biggest video path of cyber society. In the current study, YouTube Channel is selected as the cyber media that portrays linguistic features reflected on responders' communication under the issue of transgenderism.

Transgenderism in the Online Cambridge Dictionary refers to "the condition of someone feeling that they are not the same gender (sex) as the one they had or were said to have at birth" [38]. Transgender issue has been perceived and addressed differently across nations based on the ideology in each country. In Southeast Asia, society's paradigm and responses towards transgender issue vary in their levels of tolerance. In Malaysia, for example, when ideology is derived from religious teachings, transgenderism is perceived as something against society. Transgender women in Malaysia lived with stigmatism and persecution [39], where in some cases they were also reported to be socially excluded in their societal life [40]. Some images referring to transgender women in Malaysia were persecuted, hostile, rude, animal, discriminated, disgusted, harassment, stigma, harm, barrier, mischaracterization, etc. [39]. However, in the country like Thailand where society's paradigm towards transgenderism has gradually changed, transgender women in some cases were accepted and supported in both family and society [41]. This phenomenon, nevertheless, is not underpinned by the study of Nemoto et al. [41] reporting that Thai transgender women in some cases still faced persecution from the society as well as from their family members especially fathers and brothers.

Like in Malaysia, under the Indonesian context where society's perception and reaction towards sensitive phenomena are derived from cultural and religious teachings including Islam, the issue of transgenderism especially genital reconstruction surgery is seen as the fatal wrongdoing against culture and religion. Under the Indonesian ideology, any fatal wrongdoing against the religion and culture can be interpreted against the society regardless of the individuality of the case. However, certain community especially entertainers has been suspected to have undergone transgender genital reconstruction surgery and some have openly confirmed their surgery to the public. One of existing issues of Indonesian entertainers suspected to have undergone transgenic genital surgery refers to celebrity $\mathrm{X}$ whose suspected video of his transgender post genital surgery has gone viral on YouTube channel. The singer has publicly been suspected and believed to have undergone genital reconstruction surgeries from male to female organs. This most up-to-date issue of genital reconstruction issue has triggered public debate and hatred on social media especially on YouTube.

Until this point, threefold main reasons have underpinned this present study entitled "Linguistic Signs and Meanings between Material and Relational Processes in Cyber-based Interactive Responses towards Transgenderism Issue: A Semiotic and SFL Perspective”. First, previous studies on media within the framework of transitivity system of systemic functional linguistic so far have tended to focus on the process distribution instead of on the inner linguistic features of process constituents and none have specifically blended semiotic framework of signs and meanings. Second, most previous SFL studies on media have tended to use linguistic features on one-way-communication or conventional media as the data sources instead of those in the interactive cyber media. Nevertheless, studies conducted by Manar [19][22] have investigated the transitivity system on the language of cyber media but their foci are on the one- 
way communication rather than the interactive mode of communication. Third, since religion and culture in Indonesia forbid the activities associated with transgenderism, the issue of genital reconstruction surgeries have triggered public debate and outrage. In addition, studies on functional linguistics in relation with gender identity to the present time have been inclined to focus on the bias representation between male and female in texts apart from the sensitive area of transgenderism [2][42].

This present study thus attempts to shed light on the signs and meanings built by YouTube responders in addressing the suspected issue of celebrity's post genital reconstruction surgery broadcasted through YouTube. Specifically, this SFL-based and semiotic study limits its focus on responders' interactive comments framed in the material and relational processes by answering the following questions: 1) What strategies are employed in the signs between material and relational processes in addressing the transgenderism issue broadcasted through YouTube? 2) What types of meanings are represented in the signs between material and relational processes?

\section{Methodology}

The current study entitled "Linguistic Signs and Meanings between Material and Relational Processes in Cyber-based Interactive Responses towards transgenderism Issue: A Semiotic and SFL Perspective” adopts the content analysis design scrutinizing how signs and meanings towards a suspected transgender post genital surgery involving an Indonesian celebrity broadcasted on cyber video are built between material and relational processes among cyber responders. Under this blended SFL and semiotic study, content analysis is considered as "a research technique for making replicable and valid inferences from texts (or other meaningful matter) to the contexts of their use" [43]. It is claimed as the tool applicable for all context and various social disciplines in analyzing the message of texts scientifically [44]. For its research framework, this study mixes Hallidayan systemic functional linguistics especially the material and relational processes of transitivity system with semiotic sign analysis.

The sources of data in this blended study were studied from the bottom up [45], where signs in the form of linguistic features of material and relational processes in the cyber-based interactive written responses towards the issue of transgenderism were analyzed by means of classification and interpretation of linguistic occurrences. The signs in written interactive responses of cyber video in this study were not only interpreted as a pattern of rules but also as a communicative function in the meaningful context of cyber-society interaction.

As the sources of data, written interactive responses posted on YouTube announcing a post genital reconstruction surgery suspected as involving an Indonesian celebrity were collected and studied. Nevertheless, since the focus of this study lies on the written interactive responses between or among responders, the narration in the video was excluded from the analysis while responses without replies were excluded as well. The sources of data under this SFL and semiotic study were copied from https://www.youtube.com/watch?v=T2Cyi-QuIXg in 24 June 2019 due to its views that surpassed 2 million times. Any occurrences of addition, edition, or omission in the written responses of data source after that time are not under control of this study.

570 responses in Indonesian copied from a YouTube video of more than 2 million views were studied but only 144 interactive responses were analyzed since the rest did not represent two-way communication mode. Interactive comments copied from the sources were categorized into prompting and replying responses. A prompting response at least has one replying response 
or it also may have more. The prompting and replying written responses_were analyzed into 255 ranking or non-embedded clauses in which material and relational processes were separated from other types of processes namely verbal, relational, existential, and behavioral. Processes in embedded clauses were not analyzed since they are the constituent of the ranking clause. An embedded or rank-shifted clause refers to the constituents of the main clause such as qualifiers or modifiers [46], while a ranking or non-embedded clause refers to the clause that brings the main process. Besides, any occurrences of semantic errors in clauses were also analyzed but they were classified as ambiguity while occurrences of elliptical words either in terms of process or participant were signaled with a single bracket.

After the analysis of process types, the constituents of material and relational process were analyzed with a specific table adapted from Hallidayan SFL framework. In this stage, process, participants and circumstances in each process were separated. The third stage was the analysis on the signs framed in the constituents of material and relational clauses. The occurrences of signs brought by the constituents of material and relational processes towards the suspected issue of transgender post genital reconstruction surgery announced on YouTube were categorized and interpreted within their similar and distinct meanings.

\section{Findings and Discussion}

\subsection{Signs in Relational Processes}

Table 1. Sign Categories in the First and Second Participants of Relational Processes

\begin{tabular}{clcc}
\hline \multirow{2}{*}{ No. } & \multicolumn{1}{c}{ Sign Categories } & \multicolumn{2}{c}{ Relational Processes } \\
\cline { 3 - 4 } & & Participant 1/Carrier & Participant 2/Attribute \\
\hline 1 & Reliability of Video & $34.8 \%$ & \\
2 & Attributes to the reliability of video & & $35.71 \%$ \\
3 & Celebrity X & $41.96 \%$ & \\
4 & X's Body & $6.25 \%$ & \\
5 & Attributes to X's Body & & $9.82 \%$ \\
6 & Attributes to X's Mentality & & $16.70 \%$ \\
7 & Attributes to X's Identities & $5.36 \%$ & $14.29 \%$ \\
8 & Responders & & \\
9 & Attributes to Responders & $4.46 \%$ & $6.30 \%$ \\
10 & Ambiguous & $7.14 \%$ & $4.50 \%$ \\
11 & Miscellaneous & & $13.40 \%$ \\
\hline
\end{tabular}

In reference to the table above, from the highest to the lowest, the first participants of relational processes in the interactive responses addressing the suspected issue of a celebrity undertaking a genital surgery encompasses celebrity $X$, video, miscellany, X's body, responders, and ambiguity. More various, the second participants from the highest to the lowest vary from attributes to video trustworthiness, to X's mentality, to X's identity, miscellany, to X's body, to responders and ambiguity category. Ambiguity in the findings of this study refers to the first or second participants without clear reference while miscellaneous category is associated with too various occurrences or phenomena that are not easy to be grouped as one single entity or according to their similarities. 
Based on the table 1 above, the first most noticeable sign deployment in the relational processes lies between celebrity $X$ and the video. These two signs in the first participants of relational processes addressing the issue of transgender post genital surgery occur most frequently outnumbering other categories of signs. However, the attribution addressed to $X$ is more various than to the video. In general, the attribution given to the video characterizes the quality of the video or questions its trustworthiness while the attribution given to celebrity $X$ varies from the depiction of himself/herself, his/her parts of body, his/her mentality, and even to his/her identity.

As the first participant, $X$ is separated from his/her body. In giving characterization, responders differentiate him/her with his/her parts of body. Besides, the occurrences of $X$ 's mentality $(16.70 \%)$ as the second participant outnumber the attribution given to $X$ 's identity $(14.29 \%)$ and X's parts of body (9.82\%). In this phenomenon, X's mentality is inclined to be addressed or emphasized compared to his/her body transformation. The attribution given to $X$ 's mentality as the second participants is all signified for the purpose of negative attitude such as aneh, bodoh, tak berotak, ciri-ciri tak bersyukur, etc. while the attribution to X's identity and body is signified either for the negative or ambiguous attitude as shown below.

Table 2. Attribution Given to Celebrity X

\begin{tabular}{cccccc}
\hline & Carrier/Token & Process & Attribute/Value & $\begin{array}{c}\text { Attribute } \\
\text { Emphasis }\end{array}$ & Attitude \\
\hline & $\begin{array}{c}\text { (suaranya di } \\
\text { video itu) }\end{array}$ & (ellipsis) & $\begin{array}{c}\text { beda sma suaranya } \\
\text { yang sekarang }\end{array}$ & $\begin{array}{c}\text { Physic/body } \\
\text { Ambiguous }\end{array}$ & Am \\
C9 & nama aslinya $X$ & (ellipsis) & $M F$ & Identity & Ambiguous \\
AH 1 & dadanya & (ellipsis) & rata & Physic/body & Negative \\
R & $($ dia) & (ellipsis) & bencong & Identity & Negative \\
D15 & $X$ & (ellipsis) & bodoh & Mentality & Negative \\
\hline
\end{tabular}

Ambiguity of attitude in the findings of this study is not similar with the ambiguity in term of references found in the first or second participants of relational clauses. Rather, it is seen as the neutral stance of responders' attitude. It cannot be traced as pro or against. The sentence nama aslinya $X$ (adalah) $M F$, for example, does not reflect whether the writer or responder has a negative feeling to celebrity $\mathrm{X}$. The responder only expresses his belief that $\mathrm{X}$ prior to becoming a woman was previously a man, without stating judgmental values.

Another noticeable phenomenon from the findings refers to the dominant attributes given to the quality or reliability of the video as well as the minimum attributes given to in-between responders. The signs in the attribution given to the quality or trustworthiness of video $(35.71 \%)$ and to the responders $(6.30 \%)$ indicate either negative, positive, or ambiguous judgement but overall, they reflect negative judgment.

In conclusion, signs in the relational processes of interactive comments addressing the suspected issue of transgender genital surgery are generally brought by the first and second participants. About $75 \%$ of relational processes in the data set are represented with elliptical or hidden verbal groups. The rest is represented by tidak, bisa, sudah, mempunyai, menjadi that all of which are written in the informal spoken to be written forms. 


\subsection{Signs in Material Processes}

Table 3. Sign Categories in the First and Second Participants of Material Processes

\begin{tabular}{clcc}
\hline \multirow{2}{*}{ No. } & \multicolumn{1}{c}{ Sign Categories } & \multicolumn{2}{c}{ Material Processes } \\
\cline { 3 - 4 } & & Participant 1/Actor & Participant 2/Goal \\
\hline 1 & Celebrity X & $37.74 \%$ & $8.33 \%$ \\
2 & X's body & & $19.44 \%$ \\
3 & Surgery & & $16.77 \%$ \\
4 & Hell & & $13.89 \%$ \\
5 & X's identity & & $5.56 \%$ \\
6 & Sexual organ & $26.42 \%$ & $5.56 \%$ \\
7 & Responder & $15.09 \%$ & $5.56 \%$ \\
8 & Someone & $7.55 \%$ & \\
9 & God & $3.77 \%$ & $5.56 \%$ \\
10 & Video & $9.43 \%$ & $19.44 \%$ \\
11 & Miscellaneous & & \\
\hline
\end{tabular}

Table 3. above depicts the sign categories in the participants of material processes in the interactive comments addressing a suspected issue of an Indonesian celebrity undertaking a genital surgery. Signs in participants 1 , from the highest to the lowest, include celebrity $X$ (37.74\%), responders $(26.42 \%)$, someone $(15.09 \%)$, miscellany $(9.43 \%)$, God $(7.55 \%)$, and video $(3.77 \%)$. More various, the signs of second participants, from the highest to the lowest, refer to $X$ 's body (19.44\%), miscellany (19.44\%), surgery (16.77\%), hell (13.89\%), X (8.33\%), $X$ 's identity $(5.56 \%)$, sexual organ $(5.56 \%)$, responders $(5.56 \%)$ and to the video $(5.56 \%)$. Miscellaneous category in the signs of participants 2 is associated with too various occurrences or phenomena that are not easy to be grouped as one single entity or according to their similarities. Usually, its frequency of occurrence is no more than one.

As stated earlier, the signs in the actor of material processes encompasses celebrity $X$ (37.74\%), responders (26.42\%), someone (15.09\%), God (7.55\%), and video (3.77\%). First, celebrity $X$ as linguistic signs in the actors of material clauses are dominantly linked to his/her body $(19.44 \%)$, surgery $(16.77 \%)$, hell $(13.89 \%)$, and $X$ 's identity $(5.56 \%)$ as goals. Second, responders as linguistic signs in the actors of material clauses refer to what they should do or not to do as the reflection on the issue of genital reconstruction surgery. Third, someone and god as the signs in first participants in sequence are generally linked to $X$ and sexual organs/videos as the signs in the second participants. This phenomenon is mainly represented in passive construction with concealed actors. The least one, the video $(3.77 \%)$ as the signs in the actors is found in the least occurrences. This is contradictory with the findings in relational processes where the video $(34.8 \%)$ as signs in the first participants outnumber others. In the process of describing, the quality or reliability of video is dominantly addressed as signs in the participants of relational processes while in the process of doing, the emphasis is given to the person or $X$ suspected to have undertaken the genital reconstruction surgery, the doctor that did the surgery, the responders to take or avoid action as the reflection on $X$ 's case, and the god that is believed to give punishment. All negative attitude in the material process addressed to celebrity $X$ is represented through the following verbs. 
Table 4. Processes Representing Negative Attitude to $X$

\begin{tabular}{|c|c|c|c|}
\hline No. & Verbs & Occurrences in numbers & Occurrences in percentage \\
\hline 1 & masuk neraka & 4 & 14.81 \\
\hline 2 & menjalani & 4 & 14.81 \\
\hline 3 & mengubah & 2 & 7.41 \\
\hline 4 & memperlihatkan & 2 & 7.41 \\
\hline 5 & menggunakan & 2 & 7.41 \\
\hline 6 & belum sampai & 1 & 3.70 \\
\hline 7 & dibolak-balikin & 1 & 3.70 \\
\hline 8 & dibunuh & 1 & 3.70 \\
\hline 9 & dilempar & 1 & 3.70 \\
\hline 10 & disate & 1 & 3.70 \\
\hline 11 & haid & 1 & 3.70 \\
\hline 12 & klik & 1 & 3.70 \\
\hline 13 & mencari & 1 & 3.70 \\
\hline 14 & mengikuti & 1 & 3.70 \\
\hline 15 & menunggu & 1 & 3.70 \\
\hline 16 & menyalahi & 1 & 3.70 \\
\hline 17 & tidak dihisap & 1 & 3.70 \\
\hline 18 & tidak mengubah & 1 & 3.70 \\
\hline & Total & 27 & 100 \\
\hline
\end{tabular}

\subsection{Meanings between Relational and Material Clauses}

Table 5. Attitude between Relational and Material Processes

\begin{tabular}{clcc}
\hline No. & \multicolumn{1}{c}{ Meanings } & Relational & Material \\
\hline 1 & Negative Attitude to X & 40.18 & 50.94 \\
2 & Ambiguous & 23.21 & 39.62 \\
3 & Negative Attitude to the Video (quality/reliability) & 22.32 & 0.00 \\
4 & Positive Attitude to the Video (quality/reliability) & 8.93 & 7.55 \\
5 & Negative Attitude to Responders & 3.57 & 1.89 \\
6 & Positive Attitude to X & 1.79 & 0.00 \\
\hline
\end{tabular}

Overall, the signs found in both relational and material processes employed in the interactive comments addressing the suspected issue of transgender genital reconstruction surgery reflect three categories of meanings, that is, positive, negative, and ambiguous. The targets or references of the three values are addressed to the three categories of participants, namely celebrity X, the truthfulness of the video, or other responders. Relational $(40.18 \%)$ and material $(50.94 \%)$ processes in addressing the issue share first similarity in that both of them are inclined to be dominantly employed to establish negative meanings to celebrity $\mathrm{X}$ suspected to have undergone a transgenic surgery. Second, both types of processes $(39.62 \%$ in material and $23.21 \%$ in relational) are also found to be ambiguous in terms of their judgmental values. Besides, limited numbers of relational $(3.57 \%)$ and material $(1.89 \%)$ clauses are also used to address negative meanings to other responders of the video.

In representing positive meanings, $7.55 \%$ material and $8.93 \%$ relational processes are employed to indicate that the video is a truth, that it is not a hoax video. The last similarity between both types of processes is their very least even absent roles in creating positive 
meanings to celebrity $\mathrm{X}$. None material processes are employed to address him/her with positive attitude and only $1.79 \%$ relational process is used to establish positive attitude to him/her.

The noticeable gap or function between relational and material processes in addressing the sensitive issue of transgenic surgery lies in the responses towards the truthfulness of the video. $22.32 \%$ relational processes are employed to question the trustworthiness of the cyber video announcing the post event of transgenic surgery but none of material processes are used to establish negative meanings for the reliability of the video. This phenomenon confirms that relational processes are inclined to be used not only to create negative values to $\mathrm{X}$ but also to the video while material processes tend to focus on creating negative meanings to $\mathrm{X}$.

As stated earlier, findings of this SFL-based and semiotic study have hinted that both relational and material processes in the interactive comments addressing the suspected post event of celebrity's transgenic surgery published on YouTube are employed to establish positive, negative, and ambiguous meanings towards celebrity $\mathrm{X}$, the video, or other responders. In general, both types of processes are used to create negative attitude to celebrity $\mathrm{X}$ as well as to express neutral stance of meaning. Both relational and material processes are found to share similarities and differences in addressing the issue.

Responders either consciously or subconsciously made use of strategies between the two process types in representing meaning. When using relational processes, responders in general tended to make use of second participants or attributes as a strategy to address celebrity $\mathrm{X}$ with negative image. Since around 75 per cent of processes in the relational clauses are realized in elliptical 'be' or 'predicators' that are neutral in terms of creating image, negative attitude are represented by the signs in the attributes or second participants of relational processes. Manar's study [19] on the representation of attitude addressed by distinct cyber media to a bribery case of a politician with opposite ideology points out that the attributes of relational clauses are solidified with negative meanings.

The attributes of relational clauses found in the current study are utilized to represent the acts of judgment. They serve as the grounds for negative identifications and descriptions [8] addressed to a target being discussed. Besides, based on the study of Koosha and Sham [8], the process of giving values overtly reflects negative identifications and descriptions to the outgroup. Further, in their media studies, they argue that the use of relational clauses enables media to be categorical and judgmental in favor of the in-group, and, consequently, in disfavor of the out-group [8]. Under the context of this current SFL and semiotic study, the out-group can be referred to celebrity $\mathrm{X}$ while the in-group can refer to cyber responders. It has been revealed that responders in cyber media not only function as the consumers of information but also more as the producer as well [31].

In another transitivity study, the attitude of relational clauses was also found to be dominantly employed to solidify and strengthen image [47] while Fajri [20] on his transitivity study of language in media reports that relational processes in his findings were inclined to be used to create positive attributes to the participant being discussed. Sokouhi \& Amin [13] in their comparative transitivity study on the language of media show that relational processes in media were inclined to be employed to establish either positive or negative image to the participants being discussed.

Another point to be noted in the signs of attributes of relational processes in creating negative image to $\mathrm{X}$ is that their emphasis is given more on the mental characteristics of $\mathrm{X}$ rather than on X's body or physical characteristics. This phenomenon implies that from the perspectives of responders the problems of the sensitive issue of transgenic surgery exist more on the mentality of $\mathrm{X}$ instead of his physical appearance. In describing celebrity $\mathrm{X}$, responders tended to blame the inner side of $\mathrm{X}$ rather than his physical side since the former was responsible 
for the latter. Responders might believe that X's action of changing his male body into the female one was the result of his mental characteristics such as cognition or feeling.

Apart from their maneuver of employing relational process in creating image between the interactive cyber discourse discussing the sensitive issue of transgenic post-surgery, responders are also found to benefit from material processes as one of their functional strategies. In employing material processes, responders made use of all constituents of the processes in creating meaning especially the processes or predicators and the second participants or goals. Above $50 \%$ of material clauses in the data set were used by responders to establish negative experiential meaning towards celebrity $\mathrm{X}$ and all the processes contain predicators leading to judgmental effect or goals.

When expressed in active construction, some material clauses involve celebrity $\mathrm{X}$ as the agent that will go to the hell and this occurs frequently. Celebrity $\mathrm{X}$ is associated with hell due to his action to have undergone transgenic genital reconstruction surgery. When expressed in passive construction, some material clauses involve celebrity $\mathrm{X}$ as the goal with third concealed parties including the god as the actor. The predicators employed in the passive construction of material processes are even more anarchic than the one in active construction. The predicators encompass will be thrown away, will be directly thrown to the hell, must be killed, etc. This indicates that celebrity $\mathrm{X}$ as the goal is represented as something weak or powerless in later time that he will get the punishment due to his action to have changed his male organs into female organs. Manar's study [19] on the cyber-based headlines addressing a corruption case of politician also reports that when a person was positioned as the goal he or she was inclined to be represented as the one with weak position. As reiterated by Eggins [6], one of meanings behind the material process is what did $x$ do to $y$ ? and this hints that the position of $y$ is lower than the position of $x$ where the $y$ depends on the $x$.

Until this point, this SFL and Semiotic study on the signs and meaning addressed to the issue of transgender in cyber media has shown the tendency of language maneuver performed by cyber responders by employing functional strategies of representing action and values. In addressing the issue negatively, responders tended to focus on the second participants or attributes of relational clauses and were inclined to give their emphasis on the predicator and second participants or goals of material clauses. In addition, when employing the process of doing, they also made use of passive construction strategies to address negative image to the celebrity X. The predicators in the passive construction of material clauses are even more anarchic than the ones in the active construction.

\section{Conclusion}

The scrutiny on the signs of relational and material processes in the interactive cyber-based conversation addressing the suspected issue of post-event transgenic reconstruction surgery of an Indonesian celebrity broadcasted on YouTube gives insight into the functional strategies of responders in creating signs and meanings towards the Indonesian sensitive and taboo issue of transgenderism. It depicts how responders subconsciously or consciously maneuver their embedded inner language strategies for certain purposes. In general, when employing the process of associating or making relation for creating negative stances, cyber responders put their emphasis more on the signs of attributes rather than in other constituents. When benefiting from material process for establishing negative stances, they tended to focus on the predicators and goals. In general, meanings construed in the signs of material and relational clauses are solidified with negative attitude towards celebrity X, the video, and other responders. 
The insight into the functional strategies of responders in creating signs and meanings towards the Indonesian sensitive and taboo issue of transgenderism is expected to contribute new knowledge to the field of semiotic as well as experiential meaning of systemic functional linguistics. Besides, it is also expected that it can be used as one of inputs in assisting language students how to write critically and with certain designed purposes by employing functional strategies. Other fields such as cyber media communication as well as sociology might also benefit from this study.

This SFL-based and semiotic study has focused on the signs between relational and material processes. Besides, this current study has limited its data set on the interactive written conversation posted under a YouTube video. For further studies, there still lies any need for understanding signs of other process types employed in cyber-based interactive media or in other platforms of cyber media.

\section{References}

[1] B. H. Hoed, Semiotik \& dinamika sosial budaya, 1st ed. Jakarta, Indonesia: Komunitas Bambu, 2011.

[2] E. Emilia, N. Y. Moecharam, \& I. L. Syifa, "Gender in EFL classroom: Transitivity analysis in English textbook for Indonesian students," Indonesian Journal of Applied Linguistics, vol. 7, no. 1, pp. 206-214, May, 2017.

[3] E. A. Engelmo, "Gender identity in drag culture: A transitivity analysis of the discourse of Drag Queens. Unpublished Thesis," 2018,.

[4] M. A. K. Halliday \& C. M. I. M. Matthiessen, An introduction to functional grammar, 3th ed. London, England: Hodder Headline Group, 2004.

[5] J. R. Martin, C. M. I. M. Matthiessen, \& C. Painter, Working with functional grammar. London, England: Arnold, 1997.

[6] S. Eggins, An introduction to systemic functional linguistics, $2^{\text {nd }}$ ed. New York, USA: Continuum International Publisihing Group, 2004.

[7] L. Chen, "Transitivity in media texts: Negative verbal process sub-functions and narrator bias," International Review of Applied Linguistics in Language Teaching, vol. 43, no. 1, pp. 33-51, 2005.

[8] M. Kosha \& M. R. Shams, “A critical study of news discourse: Iran's nuclear issue in British newspapers," Iranian Journal of Applied Linguistics, vol. 8, no. 2, pp. 107- 142, 2005.

[9] P. M. Matu \& H. J. Lubbe, "Investigating language and ideology: A presentation of the ideological square and transitivity in the editorials of three Kenyan newspapers," Journal of Language and Politics, vol. 6, no. 3, pp. 401-418, 2007.

[10] P. M. Matu, "Transitivity as a tool for ideological analysis," Journal of Third World studies, vol. 25, no. 1, pp. 199-211, 2008.

[11] M. Mineshima, "Discourse analysis of news texts by the application of systemic functional grammar," Bulletin of Niigata Institute of Technology, vol. 14, pp. 101-123, 2009.

[12] M. Yaghoobi, "A critical discourse analysis of the selected Iranian and American printed media on the representations of Hizbullah-Israel war," Journal of Intercultural Communication, vol. 21, 2009.

[13] H. Shokouhi \& F. Amin, "A systemist "verb transitivity' analysis of the Persian and English newspaper editorials: A focus of genre familiarity on EFL learner's reading comprehension," Journal of Language Teaching and Research, vol. 1, no. 4, pp. 387-396, 2010.

[14] E. Haig, "A critical discourse analysis and systemic functional linguistics approach to measuring participant power in a radio news bulletin about youth crime," Studies in Media and Society, vol. 4, pp. 45-73, 2012.

[15] F. Sajjad, "Critical discourse analysis of news headline about Imran Khan's peace March towards Waziristan," Journal of Humanities and Social Science, vol. 7, no. 3, pp. 18-24, 2013.

[16] N. Nabifar, "Types of grammatical metaphors in health and business texts of Iranian English 
Newspaper," Journal of Social Issues and Humanities, vol. 1, no. 4, pp. 14-20, 2013.

[17] A. A. Ahangar \& A. S. Sultani, "A critical study of news discourse: Iran's tenth presidential election of 2009 (1388) in Keyhan and Etemad newspaper," International Journal of Language Learning and Applied Linguistics World, vol. 6, no. 1, pp. 151-169, 2014.

[18] R. Santosa, A. D. Priyanto, \& A. Nuraeni, "Genre and register of antagonist's language in media: An appraisal study of Indonesian newspapers," Kata, vol. 16, no. 1, pp. 23-36, 2014, doi: 10.9744/kata.16.1.23-36.

[19] M. Manar, "Wars of media: The transitivity system of fraud-case headlines addressing an Indonesian media-owner politician," in The 43rd International Systemic Functional Congress, Bandung, Indonesia, 2016, pp. 117-119.

[20] M. S. Al Fajri, "The representation of a blasphemy protest in Jakarta in local and international press," Indonesian Journal of Applied Linguistics, vol. 7, no. 3, pp. 705-713, Jan. 2018.

[21] S. Seo, "Hallidayean transitivity analysis: The battle for Tripoli in the contrasting headlines of two national newspapers," Discourse and Society, vol. 24, no. 6, pp. 774-791, 2013.

[22] M. Manar, "The transitivity systems of Indonesian and English facebook comments: An SFL contrastive study," in Linguistic Scientific Meeting Proceeding International Conference, Bandung, Indonesia, 2015, pp. 292-298.

[23] I. Martinez, "Impersonality in the research article as revealed by analysis of the transitivity structure," English for Specific Purposes, vol. 20, pp. 227-247, 2001.

[24] P. Huang, "A comparison of international and Chinese journal article abstracts: From move structure to transitivity analysis," The Linguistics Journal, vol. 4, no. 1, pp. 23-45, 2009.

[25] S. Choura, "Ditransitive complementation in medical research articles," JéTou (Journees d'etudes Toulousaines), May. 2012.

[26] B. Kazemian, B. Behnam, \& N. Ghafoori, "Ideational grammatical metaphor in scientific texts: A Hallidayan perspective," International Journal of Linguistics, vol. 5, no. 4, pp. 146-168, 2013.

[27] A. Sucipto, A. Mahdi, \& E.T.S Sujatna, "Process types in scientific English clauses: A systemic functional linguistics analysis," International Journal of Language Learning and Applied Linguistics World, vol. 6, no. 4, pp. 389-395, 2014.

[28] S. Zheng, A. Yang, \& G. Ge, "Functional stylistic analysis: Transitivity in English-medium medical research articles," International Journal of English Linguistics, vol. 4, no. 2, pp. 12-25, 2014.

[29] S. Shahab \& H. D. Asl, "Ideational grammatical metaphor in pharmaceutical research articles," Journal of Social Issues \& Humanities, vol. 3, no. 4, pp. 111-116, Apr. 2015.

[30] W. W. Xuan, "Understanding experiential meaningmaking in Chinese adolescent L2 writing: a systemic functional perspective," Asian-Pacific Journal of Second and Foreign Language Education, vol. 3, no. 5, pp. 1-16, 2018.

[31] A. R. Saifullah, "Issues of terrorism on the internet in the wave of democratization of post-reform Indonesia: A semiotic analysis," Indonesian Journal of Applied Linguistics, vol. 5, no. 2, pp. 307$315,2016$.

[32] S. C. Herring, "Computer-mediated discourse 2.0", In Handbook of discourse analysis, D. Tannem et al., $2^{\text {nd }}$ ed. Oxford, England: Blackwell, 2015, pp.127.

[33] A. R. Saifullah, Semiotik dan kajian wacana interaktif di internet. Bandung, Indonesia: UPI Press, 2019, pp. 20.

[34] Y. Feng, H. Chen, L. He, "Consumer responses to femvertising: A data-mining case of Dove's "campaign for real beauty" on YouTube," Journal of Advertising, vol. 4, no. 8, pp. 292-301, 2019.

[35] M. L. Khan, "Social media engagement: What motivates user participation and consumption on youTube?," Computers in Human Behavior, vol. 66, pp. 236-47, 2017.

[36] J. B. Walther et al., "The influence of online comments on perceptions of antimarijuana public service announcements on YouTube," Human Communication Research, vol. 36, no. 4, pp. 46992, 2010.

[37] Díaz et al., "Generación niños YouTubers: análisis de los canales YouTube de los nuevos fenómenos infantiles,” Píxel-BIT Revista de Medios y Educación, vol. 56, pp.113-128, 2019. 
[38] Cambridge dictionary online: Make your words meaningful. Retrieved from https://dictionary.cambridge.org/dictionary/english/transgenderism.

[39] Nemoto, et al., "Sociocultural context of sex work among Mak Nyah (transgender women) in Kuala Lumpur, Malaysia," in Transgender sex work and society. L. Nuttbrock. New York, USA: Herrington Park Press, 2018.

[40] L. Nuttbrock, Transgender sex work and society. New York, USA: Herrington Park Press, 2018.

[41] Nemoto, et al., "Sociocultural context of health among Kathoey (transwomen) and female sex workers in Bangkok, Thailand," in Transgender sex work and society. L. Nuttbrock. New York, USA: Herrington Park Press, 2018.

[42] H. Hu, H. Xu, J. Hao, "An SFL approach to gender ideology in the sentence examples in the contemporary Chinese dictionary," Lingua, vol. 220, pp. 17-30, Mar. 2019.

[43] K. Krippendorff, Content analysis: An introduction to its methodology. California, USA: Sage Publications, Inc, 2004, pp. 18.

[44] K. A. Neuendorf, The content analysis guide book. London, England: Sage Publication, 2002.

[45] D. Charles et al., Academic writing at the interface of corpus and discourse. New York, USA: Continuum. 2009.

[46] L. Gerrot \& P. Wignell, Making sense of functional grammar. Cammeray, NSW, Australia: Gerd Stabler, 1994.

[47] W. Kondowe, "Presidents and ideologies: A transitivity analysis of Binguwa Mutharika's inaugural address," International Journal of Language and Linguistics, vol. 2, no. 3, pp.174-180, 2014. Sage Publications, Inc, 2004. 